\title{
Medfly courtship duration: a sexually selected reaction norm changed by crowding
}

\author{
R.D. BRICEÑO ${ }^{1}$ and W.G. EBERHARD ${ }^{1,2,3}$ \\ ${ }^{1}$ Escuela de Biología, Universidad de Costa Rica \\ ${ }^{2}$ Smithsonian Tropical Research Institute
}

Received 24 January 1998, accepted 4 May 1998

The evolutionary effects of crowding on male courtship behavior were studied using wild and mass-reared medflies. Mass-reared strains had been raised under highly crowded conditions in mass-rearing facilities for approximately 75,180 , and 238 generations. Pre-mounting courtship was facultatively shortened in both wild and mass-reared males under conditions of greater crowding. The courtship behavior of males of mass-reared strains was also shorter than that of wild males under similar conditions of crowding. Shorter courtships are probably advantageous for males in crowded conditions because they reduce the likelihood of the courtship being interrupted by other flies. Several types of data indicated that males rather than females were responsible for shortened courtships. We conclude that heritable variation in male courtship behavior has persisted in a wild population despite its overall relatively low genetic variability, and that genetic changes in mass-reared strains have altered the range of facultative adjustments in courtship behavior.

KEY WORDS: courtship, reaction norm, medfly, sexual selection.

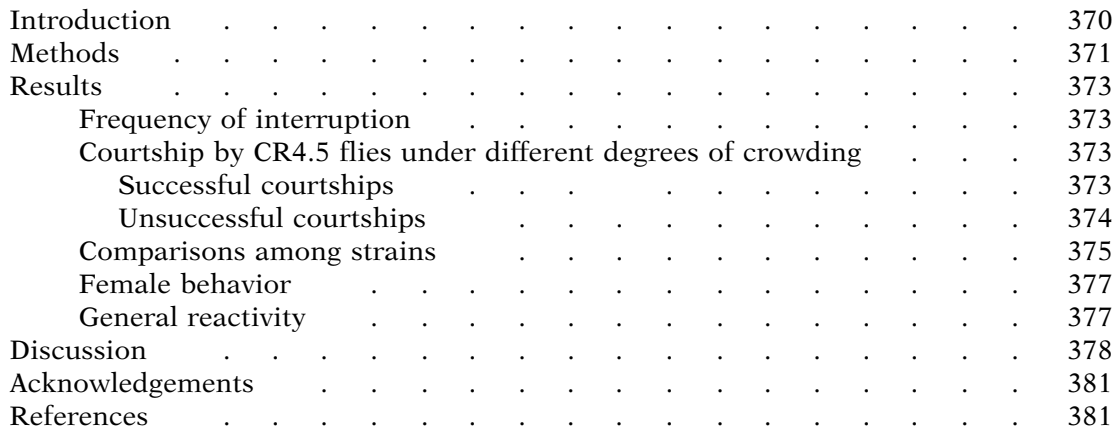

\footnotetext{
${ }^{3}$ Address for correspondence: William G. Eberhard, Biología, Universidad de Costa Rica, Ciudad Universitaria, Costa Rica (Fax: 506-228-0001; E-mail: weberhar@cariari.ucr.ac.cr).
} 


\section{INTRODUCTION}

Sexual selection often results in rapid divergent evolution of both morphological and behavioral traits (e.g. DARWIn 1871, West-EBERHARD 1983, ANDERSSON 1994). Some aspects of the way in which sexual selection acts to produce such evolution, and the intermediate stages by which it progresses are not yet well understood. The results of this study are related to two general evolutionary questions. The first is the importance of Fisherian models relative to other models of female choice. An important theoretical objection to Fisherian models is that there may usually be too little intraspecific genetic variation in male traits to allow sexual selection by female choice among males (e.g. PARKer 1984). But in recent years data have begun to accumulate showing that sexually selected traits seem to have substantial heritabilities (ANDERSSON 1994), so this issue is still unresolved. A second, more general question that is not restricted to sexually selected characters relates to the role of phenotypic plasticity in behavioral evolution, and the possible importance of phenomena such as genetic assimilation (WADDINGTON 1953).

The medfly, Ceratitis capitata Wiedemann, offers an unusual opportunity to examine these two questions under the artificial selection in mass rearing facilities. The flies are a serious agricultural pest, and one widely-used control technique involves rearing massive numbers of flies, then sterilizing and releasing them. Because it is difficult to induce wild-caught females to oviposit in captivity, mass-reared strains have often been kept for many generations in captivity. Mass-reared flies mate under conditions that differ dramatically from those in the wild. Thus strains produced in mass-rearing facilities constitute the results of inadvertant selection experiments in which those males best able to deal with conditions in captivity have been favored. By comparing the behavior of mass-reared flies with that of wild flies in the population from which the mass-reared strain was derived, one can test for possible effects on courtship behavior of the altered conditions during mass rearing.

Medflies are also of interest with respect to the genetics of wild populations. The species is native to Africa, and genetic analysis has showed that it has probably undergone two successive population bottlenecks in reaching the New World, first as it colonized the Mediterranean region, and then when it colonized other parts of the world (FUERST 1988). The genetic variation in wild populations in the New World (from which several mass-rearing strains have been derived) is relatively small (Huettel et al. 1980, Fuerst 1988). The depleted genetic variability should reduce the chances of adaptive changes in mass-reared strains, thus making artificial selection experiments especially stringent tests of the existence of genetic variation for sexually selected traits in natural populations.

Medfly courtship occurs in nature in two different contexts: in leks where each male usually occupies the underside of a different leaf; and near oviposition sites, where several flies may be present on a single fruit (Prokopy \& HENDRICHS 1979; HENDRICHS \& HENDRICHS 1990; WhITTIER et al. 1992, 1994; summary in EBERHARD in press). Some courtships are interrupted by other flies in nature (HENDRICHS \& HENDRICHS 1990), and interruption is probably more frequent at sites where more flies are present, though there are apparently no data directly addressing this question.

One difference between the conditions under which flies mate in the wild and in mass-rearing facilities is the dense crowding in rearing cages. In the highly crowded conditions of mass rearing cages, more than half of all courtships were interrupted by other flies (BRICEÑo et al. 1996, below), so it might be advantageous for males to perform abbreviated courtship sequences under more crowded conditions. This 
study tested the possible effect of crowding on courtship in two ways. Facultative behavioral adjustments were checked by comparing the courtship behavior of males of a strain that had been mass-reared for 4.5 years and of wild males when flies were caged at different densities. Genetic differences between strains were checked by comparing the behavior of four strains under similar degrees of crowding.

Pre-copulatory sexual interactions in medflies go through three relatively distinct stages (FERON 1962; Rolli 1976; Arita \& KANESHIRo 1985, 1986; BriceÑo et al. 1996; EBERHARD \& PEREIRA 1995):

(1) The male emits pheromone by everting a rectal pouch at the tip of his abdomen, attracting the female from a distance. When a female approaches, the male faces her, bends the tip of his abdomen ventrally, and vibrates his wings ("wing vibration"), producing a distinctive song and probably wafting a plume of pheromone toward her.

(2) At close range, the male retracts the pheromone-producing pouch, and buzzes his wings ("wing buzzing") to produce a different song that includes a burst of sound each time he rapidly deflects his wings anteriorly. Off and on during the period of wing buzzing the male simultaneously performs bursts of "head rocking", twisting his head rapidly from side to side and also turning it laterally and tilting it forward and backward in complex movements.

(3) Once he has lept forward and mounted the female, the male rocks his body briefly while he vibrates his wings, then turns and attempts to copulate, rubbing the female with his hind legs and nipping her ovipositor with his genitalia if she fails to extend her aculeus and allow intromission. He also appears to court her periodically during copulation.

Mating attempts frequently fail for two reasons. Often the female does not orient herself properly and remain motionless at a suitable distance from the courting male, and he refrains from leaping onto her. In addition, mounted males are often dislodged by the female. We labelled as "successful" all courtships that led to mounting attempts (but not necessarily to copulation, see Discussion). "Unsuccessful" courtships were complete courtships (with both wing vibration and buzzing) that were abandoned before attempting to mount the female and without being interrupted.

This study concentrates on stages 1 and 2 of courtship, which probably serve to arrest, align, and immobilize the female to allow the male to attempt to mount her.

\section{METHODS}

All data are from video tapes made using either a Sony Hi8 camera equipped with +6 closeup lenses or (for the 14 year strain) a National OmniPro with +6 closeup lenses (both $30 \mathrm{images} / \mathrm{sec}$ ). Three trials were performed in which crowding was manipulated by placing different numbers of flies in mating chambers (clear plastic petri dishes, $13.7 \mathrm{~cm}$ dia. and 1.8 $\mathrm{cm}$ deep): a single male and a single female in each dish (about $0.025 \mathrm{flies} / \mathrm{cm}^{2}$, on the basis of the area of the ceiling, where flies usually but not always rested); 10 males and 10 females in each dish; and 25 males and 25 females. A fourth trial also involved a single pair of flies, but in a larger plastic cylinder $9.0 \mathrm{~cm}$ in diam. and $7.3 \mathrm{~cm}$ tall. Flies were kept in mass rearing cages until immediately before taping sessions, when they were aspirated into the mating chambers. Several chambers were placed on a rotating glass table, which was turned to allow taping of males that were emitting pheromone. The close approximation of the camera, with the image of the fly usually occupying at least $1 / 5$ of the screen, allowed relatively detailed study of courtship movements. 
Courtship behavior in mass-rearing cages was also taped. The camera was focussed on a $588 \mathrm{~cm}^{2}$ area of the cloth wall of the cage (on the side of the cage with greatest illumination and through which females oviposited), and all activity occurring there was taped for 0.5-1.0 hr/session. The average density of flies in such an area was $0.55 \pm 0.083 \mathrm{flies} / \mathrm{cm}^{2}(20$ counts separated by $5 \mathrm{~min}$ each). This was thus similar to the high density treatment in petri dishes (about 0.55 flies $/ \mathrm{cm}^{2}$ ), although precise comparisons are not possible, because flies sometimes rested on the floor or sides of petri dishes.

Responsiveness to the approach of other flies was determined for CR5.5 flies and wild flies by analyzing $6 \mathrm{hr}$ of tape of groups of five males and five females that were 1 day old in a petri dish.

Four different strains of flies were used. Wild flies were raised from pupae reared from fallen tangerines and oranges collected in the Central Valley of Costa Rica near Alajuela (elevation approximately $900 \mathrm{~m}$ ) during March and April of 1995 and 1996. Two mass-reared strains that had been initiated using flies collected in the Central Valley were used; one (CR14) had been in captivity about 14 years (approximately 238 generations); the other (CR4.5) had been in captivity for about 4.5 years (about 76 generations). The second strain was also taped later (CR5, about 85 generations) in plastic cylinders; and once again 6 months later (CR5.5, about 94 generations) in combination with wild females. After the first few generations following collection in the wild, adults of both Costa Rica mass-reared strains had been bred in $2.30 \times 0.35 \times 0.50 \mathrm{~m}$ cages in which densities of flies on the side of the cage nearest the light (where flies often courted) were about $0.5 \mathrm{fly} / \mathrm{cm}^{2}$ (H. Самасно pers. comm.). A third mass-reared strain, Seibersdorf 60 (S60), was descended from a strain of flies originally collected in Egypt and subsequently mass-reared for about 12 years at the International Atomic Energy Agency facilities in Vienna. The S60 strain had been derived from this strain, still under mass-rearing conditions about 18 generations before our observations.

Numbers and durations of different movements during courtship were determined by analyzing tapes frame by frame. Each rapid anterior deflection of the wings during wing buzzing was counted as a single buzz. Each movement of the head from the usual position oriented horizontally and directly forward was counted as a single head rock. All averages are followed by one standard deviation. The data were not distributed normally, however, as illus-

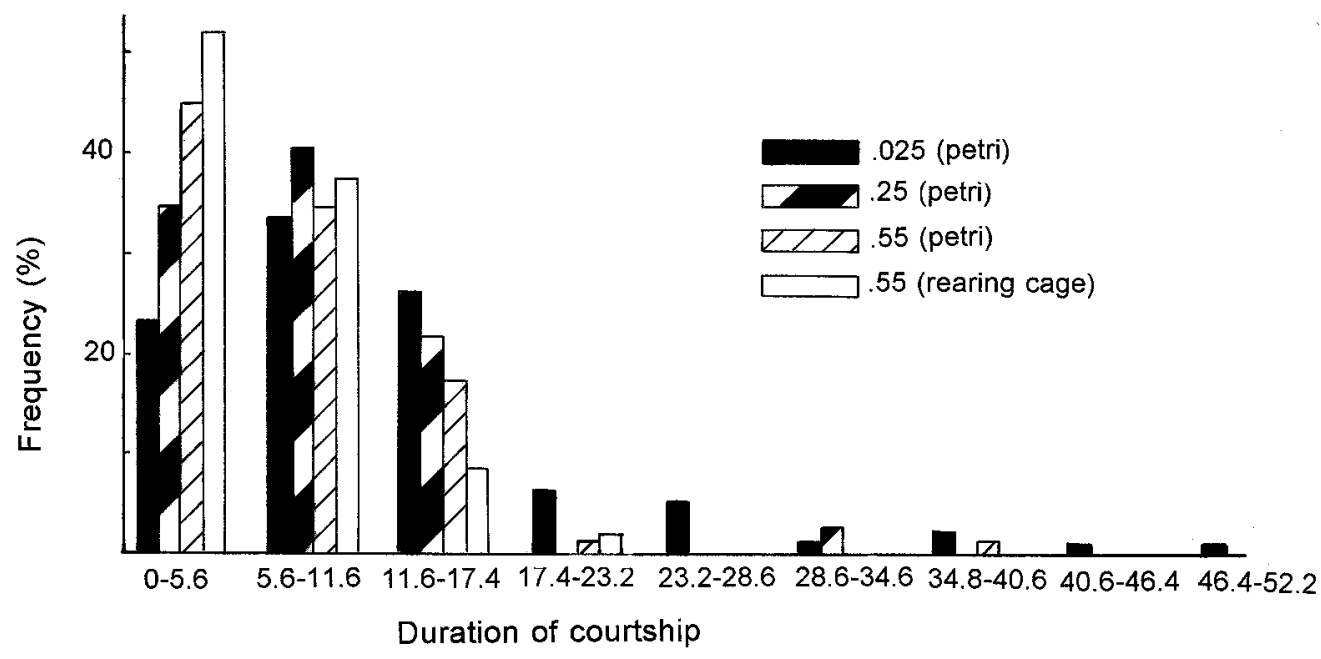

Fig. 1. - The durations of successful courtships of CR4.5 flies were reduced when the flies were more crowded in petri dishes (sample sizes were 40, 69, and 69 courtships respectively) and in a rearing cage (sample size was 48 ). 
trated in Fig. 1; averages and standard deviations are used for illustrative puposes. Average durations were calculated using only those courtships in which the behavior in question occurred. Unless otherwise specified, all tests of differences employed one-tailed tests for briefer behavior patterns under more crowded conditions or longer histories of mass-rearing.

\section{RESULTS}

\section{Frequency of interruption}

More than half of all courtships in mass-rearing cages (64\% of 226) and in crowded petri dishes (56\% of 82 ) were interrupted. Usually the male either turned away from the female and began courting another fly $65 \%$ of a total of 220 interruptions), or ceased courting altogether with the arrival of another fly (22\% of 220 interruptions).

\section{Courtship by CR4.5 flies under different degrees of crowding}

Successful courtships. Flies in less crowded conditions performed significantly longer wing vibration, wing buzzing head rocking, and total courtship before attempting to mount the female (Table 1, Fig. 1). Flies at intermediate degrees of

Table 1.

Average durations (sec) of wing vibration, wing buzzing, head rocking, and total courtship in the CR4.5 strain in successful (leading to mounting) and unsuccessful "complete" courtships at different degrees of crowding. Significance values at the bottom of the column for each behavior pattern are from Kruskal-Wallis tests; values in the same column sharing the same letter are significantly different with Dunn tests $(a, P<0.05 ; b, P<0.01 ; c, P<0.001)$.

\begin{tabular}{|c|c|c|c|c|c|}
\hline \multirow{2}{*}{$\begin{array}{l}\text { Degree of } \\
\text { crowding }\end{array}$} & \multicolumn{2}{|c|}{$\begin{array}{l}\text { Wing vibration } \\
\text { Successful? }\end{array}$} & \multicolumn{2}{|c|}{$\begin{array}{l}\text { Wing buzzing } \\
\text { Successful? }\end{array}$} & \multirow[b]{2}{*}{$\mathrm{n}$} \\
\hline & Yes & No & Yes & No & \\
\hline 2/petri & $5.6 \pm 8.4$ & $11.5 \pm 12.1 a_{1} a_{2} c_{1}$ & $7.8 \pm 6.8 b_{1}$ & $7.0 \pm 6.0 a_{4} b_{2}$ & 40,48 \\
\hline 2/cylinder & $4.6 \pm 8.4$ & $11.6 \pm 10.5 a_{3}$ & $8.5 \pm 4.4$ & $5.4 \pm 3.7$ & 54,37 \\
\hline 20/petri & $2.8 \pm 3.7$ & $6.5 \pm 7.6 a_{2}$ & $5.9 \pm 4.2$ & $11.0 \pm 10.0 c_{2}$ & 69,48 \\
\hline 50/petri & $2.6 \pm 2.4$ & $5.4 \pm 4.5 a_{1} a_{3}$ & $5.3 \pm 5.5$ & $2.9 \pm 0.7 a_{4} c_{2} c_{3}$ & 69,48 \\
\hline \multirow{4}{*}{$\begin{array}{l}\text { Rearing cage } \\
P\end{array}$} & $2.5 \pm 2.8$ & $3.1 \pm 3.9 c_{1}$ & $3.7 \pm 2.8 b_{1}$ & $4.2 \pm 2.7 b_{2} c_{3}$ & 48,32 \\
\hline & 0.33 & $<0.0001$ & $<0.0001$ & 0.0038 & \\
\hline & \multicolumn{2}{|c|}{$\begin{array}{l}\text { Head rocking } \\
\text { Successful? }\end{array}$} & \multicolumn{2}{|c|}{$\begin{array}{l}\text { Total courtship } \\
\text { Successful? }\end{array}$} & \\
\hline & Yes & No & Yes & No & $\mathrm{n}$ \\
\hline 2/petri & $1.5 \pm 1.2 a_{1} c_{1}$ & $1.2 \pm 1.0 b_{1} b_{2}$ & $12.7 \pm 10.8 b_{5}$ & $14.3 \pm 11.5 a_{4} c_{5} c_{6}$ & 40,48 \\
\hline 2/cylinder & $1.6 \pm 0.9 c_{2} c_{3}$ & $0.9 \pm 0.5 b_{3}$ & $11.4 \pm 7.6 b_{6} c_{4}$ & $13.4 \pm 11.3 a_{5} b_{7}$ & 54,37 \\
\hline 20/petri & $1.1 \pm 0.8$ & $0.9 \pm 0.8 a_{2} b_{4}$ & $8.7 \pm 6.0$ & $10.3 \pm 10.3 a_{4}$ & 69,48 \\
\hline 50/petri & $0.6 \pm 0.6 c_{1} c_{3}$ & $0.6 \pm 0.4 a_{3} b_{2} b_{4}$ & $7.8 \pm 5.8 b_{6}$ & $6.2 \pm 4.3 a_{5} c_{6}$ & 69,48 \\
\hline Rearing cage & $0.7 \pm 0.4 a_{1} c_{2}$ & $0.3 \pm 0.4 a_{2} a_{3} b_{1} b_{3}$ & $6.1 \pm 4.1 b_{5} c_{4}$ & $5.9 \pm 5.0 b_{7} c_{5}$ & 48,32 \\
\hline$P$ & $<0.0001$ & $<0.0001$ & $<0.0001$ & $<0.0001$ & \\
\hline
\end{tabular}


Table 2 .

Average number and rate (movements/sec) of head rocks and wing buzzes in the CR4.5 strain in successful (leading to mounting) and unsuccessful "complete" courtships at different degrees of crowding. Significance values at the bottom of the columns for each behavior pattern are from Kruskal-Wallis tests; values in the same column followed by the same letter are significantly different with Dunn tests $(a, P<0.05 ; b, P<0.01 ; c, P<0.001)$.

\begin{tabular}{|c|c|c|c|c|c|}
\hline \multirow{3}{*}{$\begin{array}{l}\text { Degree of } \\
\text { crowding }\end{array}$} & \multicolumn{4}{|c|}{$\begin{array}{l}\text { Head rocks } \\
\text { Successful? }\end{array}$} & \multirow{3}{*}{$\mathrm{n}$} \\
\hline & \multicolumn{2}{|l|}{ Yes } & \multicolumn{2}{|c|}{ No } & \\
\hline & Number & Rate & Number & Rate & \\
\hline 2/petri & $41.9 \pm 34.0 b_{1} c_{1} c_{2} c_{3}$ & 29.6 & $33.1 \pm 21.1 a_{1}$ & 29.7 & 40,48 \\
\hline 2/cylinder & $50.5 \pm 26.5 b_{1} c_{4} c_{5}$ & 32.6 & $26.4 \pm 14.8 a_{2}$ & 30.2 & 54,37 \\
\hline 20/petri & $32.5 \pm 26.0 c_{3}$ & 27.5 & $34.2 \pm 22.6$ & 30.2 & 69,48 \\
\hline $50 /$ petri & $29.9 \pm 22.0 c_{2} c_{5}$ & 30.2 & $15.1 \pm 9.9 a_{2}$ & 26.4 & 69,48 \\
\hline Rearing cage & $19.1 \pm 13.0 c_{1} c_{4}$ & 26.1 & $12.9 \pm 10.3 a_{1}$ & 29.2 & 48,32 \\
\hline \multirow[t]{4}{*}{$P$} & $<0.0001$ & 0.10 & $<0.0001$ & 0.97 & \\
\hline & \multicolumn{4}{|c|}{$\begin{array}{l}\text { Wing buzzes } \\
\text { Successful? }\end{array}$} & \multirow{3}{*}{$\mathrm{n}$} \\
\hline & \multicolumn{2}{|l|}{ Yes } & \multicolumn{2}{|c|}{ No } & \\
\hline & Number & Rate & Number & Rate & \\
\hline 2/petri & $12.7 \pm 10.8 a$ & 4.4 & $18.9 \pm 22.1$ & 4.2 & 40,48 \\
\hline 2/cylinder & $11.4 \pm 7.6 c$ & 4.5 & $22.3 \pm 13.9$ & 4.6 & 54,37 \\
\hline 20/petri & $8.7 \pm 6.0$ & 4.9 & $16.4 \pm 16.4$ & 5.0 & 69,48 \\
\hline $50 /$ petri & $7.8 \pm 5.8$ & 4.5 & $13.0 \pm 8.4 b$ & 4.8 & 69,48 \\
\hline Rearing cage & $6.1 \pm 4.1 a c$ & 5.0 & $22.0 \pm 14.7 b$ & 7.7 & 48,32 \\
\hline$P$ & $<0.0001$ & 0.19 & 0.024 & 0.53 & \\
\hline
\end{tabular}

crowding (20/petri) showed intermediate or close to intermediate values. The behavior of single pairs of flies in the larger volume cylinder did not differ significantly from that of single pairs in petri dishes.

The numbers of head rocks and wing buzzes were also significantly lower in more crowded conditions (Table 2). In contrast, the rates of these movements were relatively constant. This suggests that the more rapid mounting in more crowded conditions was not simply due to differences in overall degrees of activity (see section on general reactivity below).

Unsuccessful courtships. In many cases a male courted with both wing vibration and buzzing ("complete" courtships), but abandoned courtship without attempting to mount the female and without being interrupted.

Unsuccessful complete courtships also tended to be shorter under more crowded conditions (Table 1), and have lower numbers of movements (Table 2). Values for unsuccessful complete courtships at intermediate densities were generally of intermediate lengths (with the exception of wing buzzing). Values for pairs in cylinders were again not significantly different from those of pairs in petri dishes. 
Courtships that the male broke off before beginning wing buzzing ("incomplete" courtships) showed the same pattern (Table 3). Duration of wing vibration was shorter at higher densities.

Less complete data from wild flies suggested a similar ability to facultatively shorten courtship duration under more crowded conditions. Mean total courtship time in unsuccessful courtships was $19.0 \pm 13.9 \mathrm{sec}(\mathrm{n}=98)$ in single pairs and 11.5 $\pm 11.4 \sec (\mathrm{n}=36)$ with 50 flies/petri dish $(P=0.0076$ with Mann-Whitney U Test $)$.

\section{Comparisons among strains}

Pairs of males and females of the wild strain in petri dishes courted longer than flies of the CR4.5 strain at the same level of crowding in both successful and unsuccessful courtships (Table 4). Wild males rocked significantly longer, made more rocking movements, and their total courtship was longer. The rates of rocking and buzzing did not differ significantly.

Courtship behavior duration of the youngest mass-reared strain (CR4.5) tended to be longer than that of the S60 strain at a moderate degree of crowding in petri dishes (Table 5). Differences in rearing cages between the youngest strain and the older S60 and CR14 were less dramatic, and in successful courtships only head rocking showing a consistent, strong tendency to be more truncated in the two older strains (average $0.4 \pm 0.6$ and $0.4 \pm 0.2$ respectively, compared with $0.7 \pm 0.4$ ) $(P<0.001$ with Dunn tests for both). Once again there were no significant differences in the rates of head rocking and wing buzzing.

One further difference involved the frequency with which head rocking was completely omitted. Head rocking was absent in $0 \%$ of 37 courtships (successful and unsuccessful) of wild flies, in $10.2 \%$ of 334 courtships of CR4.5 flies, and in $32.1 \%$ of 78 courtships of S60 flies (S60 differs from each of the others $P<0.001$, and wild from CR4.5 $P<0.05$ with $\chi^{2}$ ). There were no consistent trends for the frequency of omissions to vary within the CR4.5 or the S60 strains at different degrees of crowding, or in successful vs unsuccessful courtships.

Table 3 .

Duration (sec) of wing vibration behavior of CR4.5 males at different degrees of crowding in "incomplete" courtships (male abandoned courtship without performing wing buzzing or head rocking) ( $\mathrm{n}=$ number of courtships). Significance value at the bottom of the column is from KruskalWallis test; values in this column followed by the same letter are significantly different with Dunn tests $(b, P<0.01)$.

\begin{tabular}{lccc}
\hline $\begin{array}{l}\text { Mating } \\
\text { chamber }\end{array}$ & $\begin{array}{c}\text { Crowding } \\
\text { (\#/chamber })\end{array}$ & $\begin{array}{c}\text { Duration of } \\
\text { wing vibration }\end{array}$ & $\mathrm{n}$ \\
\hline Petri & 2 & $14.7 \pm 12.9 b$ & 22 \\
Cylinder & 2 & $12.1 \pm 11.4$ & 23 \\
Petri & 20 & $7.6 \pm 8.3$ & 32 \\
Petri & 50 & $6.4 \pm 4.3 b$ & 35 \\
$P$ & & 0.0002 & \\
\hline
\end{tabular}


Table 4.

Average durations of courtship behavior patterns in successful (leading to mounting) and unsuccessful courtships in wild males courting wild females, CR4.5 males courting CR4.5 females, and CR5.5 males courting wild females (all single pairs in petri dishes). Values in the same row followed by the same letter are significantly different $(a, P<0.05 ; b, P<0.01 ; c, P<0.001)$.

\begin{tabular}{|c|c|c|c|c|}
\hline & $\begin{array}{l}\text { Wild } \times \text { wild } \\
\quad(\mathrm{n}=22)\end{array}$ & $\begin{array}{c}\mathrm{CR} 4.5 \times \mathrm{CR} 4.5 \\
(\mathrm{n}=40)\end{array}$ & $\begin{array}{l}\text { CR5.5 } \times \text { wild } \\
\quad(\mathrm{n}=53)\end{array}$ & $P$ \\
\hline \multicolumn{5}{|c|}{ Successful courtships } \\
\hline Wing vibration & $2.8 \pm 6.3 b$ & $5.6 \pm 8.4 c$ & $2.2 \pm 2.7 b c$ & 0.008 \\
\hline Head rocking & $2.9 \pm 2.1 a_{1} c$ & $1.5 \pm 1.2 a_{1} a_{2}$ & $0.7 \pm 0.8 a_{2} c$ & $<0.0001$ \\
\hline Wing buzzing & $11.9 \pm 13.6$ & $7.8 \pm 6.8$ & $8.3 \pm 6.6$ & 0.357 \\
\hline Total courtship & $19.7 \pm 16.1 a c$ & $13.7 \pm 10.8 a$ & $9.0 \pm 7.4 c$ & 0.0007 \\
\hline \multicolumn{5}{|l|}{ Number of: } \\
\hline Head rocks & $93.1 \pm 61.1 c_{1} c_{2}$ & $42.0 \pm 34.3 c_{2}$ & $22.0 \pm 15.6 c_{1}$ & $<0.0001$ \\
\hline Wing buzzes & $41.8 \pm 39.0 a$ & $26.3 \pm 22.0$ & $22.7 \pm 18.3 a$ & 0.038 \\
\hline \multicolumn{5}{|l|}{ Rate $(/ \mathrm{sec})$ of: } \\
\hline Head rocking & $32.6 \pm 12.8$ & $29.6 \pm 5.0$ & $32.6 \pm 7.0$ & 0.41 \\
\hline Wing buzzing & $4.5 \pm 1.7$ & $8.2 \pm 7.3$ & $8.0 \pm 6.9$ & 0.32 \\
\hline \multicolumn{5}{|c|}{ Unsuccessful courtships } \\
\hline Wing vibration & $17.6 \pm 14.7 c$ & $11.5 \pm 12.1$ & $13.3 \pm 19.9 c$ & $<0.0001$ \\
\hline Head rocking & $1.0 \pm 0.6$ & $1.2 \pm 1.0$ & $0.7 \pm 0.8$ & 0.53 \\
\hline Wing buzzing & $7.5 \pm 6.3$ & $7.0 \pm 6.0$ & $10.7 \pm 14.6$ & 0.75 \\
\hline Total courtship & $19.0 \pm 13.9$ & $14.3 \pm 11.5$ & $15.2 \pm 14.8$ & 0.16 \\
\hline \multicolumn{5}{|l|}{ Number of: } \\
\hline Head rocks & $37.9 \pm 30.3 b c$ & $33.1 \pm 21.1 b$ & $24.0 \pm 24.4 c$ & 0.007 \\
\hline Wing buzzes & $20.2 \pm 18.1$ & $18.9 \pm 22.1$ & $19.0 \pm 27.9$ & 0.106 \\
\hline \multicolumn{5}{|l|}{ Rate (/sec) of: } \\
\hline Head rocking & $27.0 \pm 9.8$ & $29.7 \pm 5.4$ & $32.6 \pm 6.0$ & 0.30 \\
\hline Wing buzzing & $3.3 \pm 2.5$ & $8.2 \pm 10.3$ & $8.0 \pm 10.0$ & 0.68 \\
\hline
\end{tabular}

Table 5

Average durations (sec), numbers, and rates (movements/sec) of different behavior patterns in a young (CR4.5) and an old (S60) mass-reared strain in successful (leading to mounting) and unsuccessful "complete" courtships with 20 flies/petri dish. Significance values are from Mann-Whitney U tests.

\begin{tabular}{|c|c|c|c|c|c|c|}
\hline & \multicolumn{3}{|c|}{ Successful } & \multicolumn{3}{|c|}{ Unsuccessful } \\
\hline & $\begin{array}{c}\mathrm{S} 60 \\
(\mathrm{n}=42)\end{array}$ & $\begin{array}{c}\text { CR4.5 } \\
(\mathrm{n}=69)\end{array}$ & $P$ & S60 & CR4.5 & $P$ \\
\hline Wing vibration & $2.2 \pm 2.6$ & $2.8 \pm 3.7$ & NS & $2.3 \pm 4.8$ & $6.5 \pm 7.6$ & 0.0018 \\
\hline Head rocking & $0.5 \pm 0.6$ & $1.1 \pm 0.8$ & 0.00074 & $0.2 \pm 0.4$ & $0.9 \pm 0.8$ & 0.00034 \\
\hline Wing buzzing & $3.6 \pm 3.1$ & $5.9 \pm 4.2$ & 0.0058 & $5.2 \pm 8.8$ & $11.0 \pm 10.0$ & 0.0023 \\
\hline Total courtship & $4.2 \pm 3.8$ & $8.7 \pm 6.0$ & $<0.0001$ & $7.0 \pm 13.1$ & $10.3 \pm 10.3$ & 0.0108 \\
\hline \multicolumn{7}{|l|}{ Number of: } \\
\hline Head rocks & $21.6 \pm 22.4$ & $32.5 \pm 26.0$ & NS & $13.4 \pm 13.9$ & $34.2 \pm 22.6$ & 0.0016 \\
\hline Wing buzzes & $11.2 \pm 19.0$ & $19.2 \pm 15.7$ & 0.0012 & $11.2 \pm 13.7$ & $16.4 \pm 16.4$ & NS \\
\hline \multicolumn{7}{|l|}{ Rate (/sec) of: } \\
\hline Head rocking & $32.6 \pm 12.8$ & $29.6 \pm 5.0$ & NS & $28.6 \pm 14.0$ & $30.2 \pm 7.1$ & NS \\
\hline Wing buzzing & $3.3 \pm 3.1$ & $4.9 \pm 5.3$ & NS & $3.1 \pm 3.0$ & $7.7 \pm 2.6$ & $<0.0001$ \\
\hline
\end{tabular}




\section{Female behavior}

Possibly the differences in male courtship behavior just documented were not due to male differences, but rather to differences in signals from females, such as earlier signs of acceptance under more crowded conditions. This possibility was tested by observing CR5.5 males paired with wild females, and by checking male behavior when possible female acceptance behavior was and was not performed.

The courtship of male CR5.5 flies paired with wild females was shorter than that of wild males paired with wild females. Total courtship duration, wing vibration, and head rocking were all shorter in both successful and unsuccessful courtships (Table 4). There were only two significant differences between CR4.5 males paired with CR4.5 females and CR5.5 males paired with wild females (wing vibration and head rocking duration), and in both cases CR5.5 males paired with wild females showed even more abbreviated behavior, opposite what would be expected if females were inducing males to perform shorter courtships.

Seven different female behavior patterns occurred frequently during 243 courtships and might have been signals of acceptance: strike at the male (lunge forward briefly toward a male, at least sometimes striking him with her head) (15.6\%); retreat/crouch (lean slowly rearward, at least sometimes crouching slightly in the process) (28.4\%); tap legs (raise front legs and touch the male's front legs repeatedly) (17.7\%); clean (rub tarsi together and on head and mouthparts in cleaning movements) $(49.4 \%)$; wings up/down (briefly move the laterally positioned or supinate wings up and down; HEADRICK \& GOEDEN 1994) (10.7\%); small steps (take one or more small steps toward the male) (14.4\%); and fold wings back (direct wings more rearward from their usual lateral positions) (4.1\%). Strike, retreat/ crouch, and tap legs were significantly more common in successful courtships than unsuccessful courtships (respective $\chi^{2}$ values $11.7,30.4$, and 20.8 , all $P<0.001$ ) and thus may constitute signals of acceptance. Clean and wings up/down, were more common in unsuccessful courtships (respective $\chi^{2}$ values $6.6,11.8, P<0.05,0.001$ ), and could be signals of rejection. Small steps and fold wings back showed no differences (respective $\chi^{2}$ values 0.2 and 2.3 , both $P>0.1$ ).

The duration of male courtship behavior was not affected by whether or not the female performed strike, retreat/crouch, or tap legs behavior at either low densities or high densities (Table 6). Thus these female behavior patterns apparently did not trigger male mounting attempts, and the differences in female behavior appear not to explain the differences in male behavior documented in previous sections.

\section{General reactivity}

Another possibility is that abbreviated courtships were due to general changes in the responsiveness of flies to other individuals, rather than to behavior limited to the context of sexual interactions. This possibility was tested by comparing wild and mass-reared flies with respect to the distances and directions between flies when one individual responded to the presence of another. Greater responsiveness would be signalled by reacting when the other fly was at a greater distance or a larger angle with the responding fly's longitudinal axis. Wild and CR5.5 flies did not differ in the distance at which one fly turned toward an approaching fly (means were $9.0 \pm 5.2 \mathrm{~cm}$ compared with $9.7 \pm 6.6 \mathrm{~cm}, \mathrm{n}=23,27)$, jerked its body $(6.6 \pm$ 4.7 compared with $7.6 \pm 6.1 \mathrm{~cm}, \mathrm{n}=29,19)$, or performed an aggressive wing dis- 
Table 6 .

Total courtship time (sec) when possible female acceptance behavior patterns were and were not performed by CR4.5 flies (successful courtships only). None of the differences between "yes" and "no" are significant.

\begin{tabular}{lcc}
\hline & $\begin{array}{c}\text { Pairs in petri } \\
\text { dish or cylinder }\end{array}$ & $\begin{array}{c}20 \text { or } 50 \\
\text { flies/petri }\end{array}$ \\
\hline $\begin{array}{c}\text { Female strikes? } \\
\text { Yes }\end{array}$ & \\
No & $14.7 \pm 15.9(\mathrm{n}=21)$ & $7.3 \pm 3.9(\mathrm{n}=5)$ \\
$\begin{array}{c}\text { Female retreats/crouches? } \\
\text { Yes }\end{array}$ & $13.7 \pm 11.7(\mathrm{n}=47)$ & $11.9 \pm 10.4(\mathrm{n}=32)$ \\
No & $14.6 \pm 12.6(\mathrm{n}=37)$ & $11.5 \pm 12.4(\mathrm{n}=12)$ \\
$\begin{array}{c}\text { Female taps legs? } \\
\text { Yes }\end{array}$ & $13.3 \pm 13.7(\mathrm{n}=38)$ & $10.9 \pm 8.0(\mathrm{n}=18)$ \\
No & $12.7 \pm 12.9(\mathrm{n}=21)$ & $11.5 \pm 17.0(\mathrm{n}=12)$ \\
& $14.6 \pm 13.3(\mathrm{n}=50)$ & $11.0 \pm 7.4(\mathrm{n}=23)$ \\
\hline
\end{tabular}

play $(9.5 \pm 7.8$ compared with $9.9 \pm 7.2 \mathrm{~cm}, \mathrm{n}=24,28)$ (all $P>0.05$; Wilcoxon tests). Values for angles also did not differ significantly (averages were, respectively, $56 \pm 48$ vs $55 \pm 47,55 \pm 53$ vs $53 \pm 54$, and $56 \pm 57$ vs $58 \pm 60$ ) (all $P>0.05$; Wilcoxon tests).

\section{DISCUSSION}

\section{Genetic assimilation and facultative adjustments of courtship}

This study documents both facultative and evolutionary reductions in courtship duration associated with crowding. The evolutionary change resembles genetic assimilation (WADDINGTON 1953) in that the average courtship duration after selection shifted toward the extreme values that were originally obtained only under severe crowding. It differs from genetic assimilation in that facultative variation in duration nevertheless persisted. The new reaction norm was thus not "fixed" on a particular phenotype under normal conditions. Such shifts in gene frequencies influencing regulation of form under selection on an environmentally influenced response (termed "genetic accomodation" by M.J. WEST-EBERHARD in prep.) may be common evolutionary events. Perhaps this more flexible type of change will prove to be more typical of genetic assimilation of behavioral traits.

These results have other theoretical consequences. As in a number of other species (JENNIONS \& PETRIE 1997), male courtship behavior proved to be facultatively adjustable rather than fixed. Both wild and mass-reared strains of medflies facultatively adjusted their behavior to different degrees of crowding. Perhaps the ability to adjust courtship behavior to crowding originally evolved in response to the greater crowding at oviposition sites than at leks. Longer courtships are presumably favored under less crowded conditions because they increase the chances that the female will allow the male to mount and to copulate. Shorter courtships are probably favored under the crowded conditions experienced by flies breeding in 
mass-rearing facilities because the advantage from the reduction in the frequency of interruptions by other flies outweighs the loss in female receptivity. Shortened courtships may explain the reduced mating effectiveness of some mass-reared strains (T. SHELLY, P. LEIDO \& A. ECONOMOPOULOS pers. comm.).

\section{Artificial selection on male behavior}

The briefer courtships have evolved in mass-reared strains in as little as about 80 generations. The fact that the evolutionary changes seen in mass-reared strains were those that would be predicted on the basis of adaptive responses to crowding indicates that the change was due to selection rather than drift.

The mass-reared S60 strain derived from Egyptian flies was less similar to wild flies from Costa Rica than were the two Costa Rican mass-reared strains, but it is not certain whether or not this difference is due to geographic differentiation between wild populations, or to a longer history of mass rearing. The Egyptian populations from which the S60 strain was derived probably harbored greater genetic diversity than do those in the New World (Huettel et al. 1980, Fuerst 1988). Medflies first appeared in Costa Rica in the 1950's, and their origins are not known.

The behavioral differences between wild flies and the three mass-reared strains indicate that there is appreciable genetic variation for these male courtship traits, at least in field populations in Costa Rica. The question of whether variation in male traits under sexual selection exists in natural populations has been controversial. Our results are in accord with the trend in other groups for variation to exist (ANDERSSON 1994). The existence of enough variation in Costa Rican massreared populations to allow subsequent evolution is especially significant, because these flies have recently passed through at least two and perhaps three population bottlenecks: colonization of the Mediterranean region and subsequent colonization of the New World (Huettel et al. 1980, FuERst 1988); and formation of massreared strains derived from undetermined but possibly small numbers of ovipositing females (H. CAMACHO pers. comm.).

\section{Possible effects of female behavior and general reactivity}

Three lines of evidence indicate that selection on males rather than females was responsible for the evolution of shorter courtships. Failed courtships showed the same patterns of differences with crowding and between strains as did successful courtships (that led to mounting attempts), suggesting that changes in female acceptance signals were not responsible for differences in male behavior. There was no correlation between the occurrence of three female behavior patterns that may indicate female receptivity to mounting and the duration of successful courtships. The possibility of more subtle female effects remains. Males appear to use both the distance to the female, and the degree to which the two flies' longitudinal body axes are mutually aligned (the degree to which the flies face each other) as cues to trigger mounting attempts (BRICEÑO et al. 1996). Thus if females altered the rapidity with which they assumed or allowed males to assume appropriate positions under different degrees of crowding, they could perhaps alter the duration of premount courtship. The lack of changes in the courtship behavior of male CR5.5 flies when they courted wild females rather than mass-reared females argues, however, that the changes in male behavior are not due to differences in female behavior. 
Another possibility is that the differences we found in the CR4.5 strain under different conditions of crowding are not certain to be under sexual selection, because they may not be specific to the context of male-female interactions. The changes in courtship when flies are more crowded might be due to a change in "nervousness" or general reactivity of flies that is associated with the presence of conspecifics. Several types of data are related to this idea. Decisions to desist, or cease courting without attempting to mount the female could be influenced by general reactivity. In some courtships the male ceased courting after beginning wing buzzing and head rocking (unsuccessful "complete" courtships in Tables 1-2). The generally similar trend toward shorter durations in unsuccessful courtships under more crowded conditions supports this general reactivity hypothesis. In other courtships, the male abandoned courtship before performing wing buzzing and head rocking ("incomplete" courtships in Table 3). Again as predicted by the general reactivity hypothesis, the duration of wing vibration was shorter in more crowded conditions and in mass-reared strains than in wild flies.

Nevertheless, when we tested the general reactivity hypothesis directly by examining other aspects of male behavior, we found that other behavioral decisions are not made more rapidly by mass-reared flies than wild flies, as predicted by the increased general reactivity hypothesis. In addition, flies of mass-reared strains tend to respond less readily to predators (KANESHIRO 1991) and show less aggressive behavior to conspecifics (RAMOs 1993, BRICEÑO et al. in prep.), suggesting that mass-rearing conditions in fact select for lower general reactivity. Overall activity levels, as indicated by rates of wing buzzing and head rocking also did not vary among strains or under different degrees of crowding. In sum, available evidence indicates that courtship differences among strains are not easily explained as the result of differences in overall levels of reactivity or responsiveness.

\section{Courtship and insemination}

It is important to remember that the data presented here concern only attempted mountings, and do not take into account possible post-mounting rejections by females. A large proportion of mounting attempts by male medflies fail to result in copulation, usually because the female dislodges the male almost immediately after he mounts her (80-96\% with different strains in captivity; KANESHIRO 1991, R.D. BRICEÑo \& W. EBERHARD unpub.). In addition, some successful mounts fail because the female fails to extend her ovipositor and thus prevents intromission (EBERHARD \& PEREIRA 1993); and up to about 10-20\% of successful intromissions fail to result in sperm transfer to the female's spermathecae (СAMACHO 1991, R. Poramarcom unpub.; see summary in EBERHARD in press). Thus, a male that succeeds in inducing a female to position herself directly in front and facing him so he can attempt to mount her has not successfully induced her to allow insemination. At the same time, any failure to mount a female certainly represents a definitive failure to inseminate her.

This study has a practical application, as it suggests a way to improve the traditional design of breeding cages in mass rearing facilities. The cues used by flies to sense the degree of crowding remain unknown, but they probably involve the surface space rather than the total volume available to the flies. Durations of courtships in crowded, low volume petri dishes were similar to those in crowded rearing cages, which had similar densities of flies resting on the walls but much larger vol- 
umes of space. In addition, courtship duration of isolated pairs in petri dishes were similar to those of pairs in larger cylinder cages. This suggests that a practical means of reducing the effective density of flies in mass rearing cages would be to increase the space in the cage on which flies can alight. This might reduce the rapidity with which flies in captivity evolve shorter courtship behavior.

\section{ACKNOWLEDGEMENTS}

We are indebted to Hernan Camacho for his continued enthusiastic encouragement to work with medflies; he and his staff at OIRSA facilitated our use of the facilities and the flies. We also thank Jorge Hendrich for support. Our work was financed by the International Atomic Energy Agency, the Smithsonian Tropical Research Institute, and the Vicerrectoría de Investigación of the Universidad de Costa Rica.

\section{REFERENCES}

Andersson M. 1994. Sexual selection. Princeton, NJ: Princeton University Press.

ARITA L. \& KANEShIRo K. 1985. The dynamics of the lek system and mating success in males of the Mediterranean fruit fly, Ceratitis capitata (Wiedemann). Proceedings of the Hawaiian Entomological Society 25: 39-48.

ARItA L. \& KANEShiro K. 1986. Structure and function of the rectal epithelium and anal glands during mating behavior in the Mediterranean fruit fly male. Proceedings of the Hawaiian Entomological Society 26: 27-30.

Briceño R.D., Ramos D. \& Eberhard W.G. 1996. Courtship behavior of male medflies (Ceratitis capitata; Diptera: Tephritidae) in captivity. Florida Entomologist 79: 130-143.

Самасно H. 1991. Transferencia de espermatozoides en la mosca del Mediterraneo, Ceratitis capitata (Diptera: Tephritidae). Masters Thesis, University of Costa Rica.

Darwin C. 1871. The descent of man and selection in relation to sex. New York: Modern Library (reprinted).

Eberhard W.G. (in press). Sexual behavior of the medfly, Ceratitis capitata. In: Aluja M. \& Norrbom A., Edits. Fruit flies (Teprhitidae): phylogeny and evolution of behavior. Boca Raton, FL: CRC Press.

Eberhard W.G. \& Pereira F. 1993. Functions of the male genitalic surstyli in the Mediterranean fruit fly, Ceratitis capitata (Diptera: Tephritidae). Journal of the Kansas Entomological Society 66: 427-433.

Eberhard W.G. \& Pereira F. 1995. The process of intromission in the Mediterranean fruit fly, Ceratitis capitata (Diptera: Tephritidae). Psyche 102: 101-122.

FERON M. 1962. L'instinct de reproduction chez la mouche mediterranéenne des fruits Ceratitis capitata Wied. (Dipt. Trypetidae). Comportement sexuel - Comportement de ponte. Revue de Pathologie Végétale et d'Entomologie Agricole de France 41: 1-129.

FUERST P.A. 1988. Islands as models in population genetics, pp. 264-269. In: Downhower J., Edit. The biogeography of the Island Region of Western Lake Erie. Columbus, $\mathrm{OH}$ : Ohio State University Press.

HeadRICK D.H. \& Goeden R.D. 1994. Reproductive behavior of California fruit flies and the classification and evolution of Tephritidae (Diptera) mating systems. Studia Dipterologica 1: 194-252.

HendRICHS J. \& HendRichs M.A. 1990. Mediterranean fruit fly (Diptera: Tephritidae) in nature: location and diel pattern of feeding and other activities on fruiting and nonfruiting hosts and nonhosts. Annals of the Entomological Society of America 83: 632-641.

Huettel M.P., Fuerst A.P., Maruyama T. \& Chakraborty F. 1980. Genetic effects of multiple bottlenecks in the Mediterranean fruit fly (Ceratitis capitata). Genetics 94: 547-548. 
Jennions M.D. \& Petrie M. 1997. Variation in mate choice and mating preferences: a review of causes and consequences. Biological Reviews 72: 283-327.

KANESHIRO K.Y. 1991. Quality control of mass-reared strains of fruit flies, pp. 137-145. In: Kawasaki K. et al., Edits. Proceedings of the International Symposium on the Biology and Control of Fruit Flies. Okinawa: Ginowan.

PARKER G.A. 1984. Sperm competition and the evolution of animal mating strategies, pp. 1-60. In: Smith R.L., Edit. Sperm competition and the evolution of animal mating systems. New York: Academic Press.

Prokopy R. \& Hendrichs J. 1979. Mating behavior of Ceratitis capitata in field cages on host trees. Annals of the Entomological Society of America 72: 642-648.

Ramos D. 1993. Efectos de la cría masiva sobre el comportamiento agresivo y sexual de la mosca del Mediterráneo Ceratitis capitata (Diptera, Tephritidae). Masters Thesis, University of Costa Rica.

Rolli V.K. 1976. Die akustischen Sexualsignale von Ceratitis capitata Wied. und Dacus oleae Gmel. Zeitschrift für Angewandten Entomologie 81: 219-223.

WAdDINGTON C.H. 1953. Genetic assimilation of an acquired character. Evolution 7: 118-126.

West-Eberhard M.J. 1983. Sexual selection, social competition, and speciation. Quarterly Review of Biology 58: 155-183.

Whittier T.S., Kaneshiro K. \& Prescott L.D. 1992. Mating behavior of Mediterranean fruit flies (Diptera: Tephritidae) in a natural environment. Annals of the Entomological Society of America 85: 214-218.

Whittier T.S., NAm F.Y., Shelly T.E. \& Kaneshiro K.Y. 1994. Male courtship success and female discrimination in the Mediterranean fruit fly (Diptera: Tephritidae). Journal of Insect Behavior 7: 159-170. 